\title{
Penerapan Sistem Data Cleansing untuk Mencegah dan Menghilangkan Duplikasi Rekam Medis
}

\author{
Nur Rokhman*, Annisa Maulida Ningtyas, Marko Ferdian Salim, Dian Budi Santoso \\ Departemen Layanan dan Informasi Kesehatan, Sekolah Vokasi, Universitas Gadjah Mada
}

Submitted: 31 Oktober 2019; Revised: 12 November 2020; Accepted: 30 Desember 2020

Katta Kunci:
Data cleansing
Duplikasi
Rekam medis
Sistem informasi
Kesehatan

Keywords:

Data cleansing

Duplication

Medical records

Health

information

system

Posbindu
Abstrak Sistem Informasi Kesehatan adalah sistem yang mengintegrasikan pengumpulan, pengolahan, pelaporan data, dan penggunaan informasi yang diperlukan untuk meningkatkan efektivitas dan efisiensi pelayanan kesehatan melalui pengelolaan yang lebih baik pada semua tingkat layanan kesehatan. Dinas Kesehatan Kulon Progo merupakan salah satu Dinas Kesehatan yang telah memanfaatkan Sistem Informasi Kesehatan dalam penyelenggaraan transaksi kesehatan. Namun, implementasi Sistem Informasi Kesehatan masih memiliki kekurangan, yaitu ditemukan data seorang pasien yang memiliki banyak nomor rekam medis atau sering disebut duplikasi data rekam medis. Kegiatan pengabdian kepada masyarakat ini dilaksanakan dengan memanfaatkan teknologi tepat guna di Dinas KesehatanKulon Progo. Kegiatan ini bertujuan untuk mengimplementasikan teknik data cleansing dengan framework "RESIK" untuk membantu dalam pencegahan dan mendeteksi duplikasi rekam medis serta memberikan pelatihan kepada tenaga perekam medis perihal penerapan sistem data cleansing. Pelatihan diikuti oleh 105 peserta yang masing-masing merupakan perwakilan pegawai puskesmas di wilayah Dinas Kesehatan Kulon Progo. Framework "RESIK" selanjutnya diujicobakan di Puskesmas Sentolo 2 sebagai lokasi implementasi sistem. Dalam kegiatan ini ditemukan data rekam medis yang duplikat di Puskesmas Sentolo 2. Pembersihan kemudian dilakukan. Pihak Dinas Kesehatan Kulon Progo disarankan untuk mengimplementasikan data cleansing dengan framework "RESIK" di seluruh puskesmas di wilayah Kulon Progo.

Abstract Health Information System is a system that integrates the collection, processing, reporting of data, and use of information needed to increase the effectiveness and efficiency of health services through better management at all levels of health services. Kulon Progo Health Office is one of the Health Services that has utilized the Health Information System in organizing its health transactions. However, the implementation of the Health Information System still has shortcomings, namely that it was found that a patient has many medical record numbers or often referred to as duplicated medical record data. Community service activities are carried out through the use of appropriate technology at the Kulon Progo Health Office. This activity aims to implement data cleansing techniques using the "RESIK" framework to help prevent and detect duplication of medical records and provide training to medical recorders in cleaning data. The training was attended by 105 participants, each of whom was a representative of the Puskesmas staff in the Kulon Progo Health Office area. The "RESIK" framework was then piloted at Puskesmas Sentolo 2 as the location for the implementation of the system. From this activity, duplicate medical record data can be found at Puskesmas Sentolo 2, and then cleaning is carried out. Kulon Progo Health Office is advised to implement 


\section{PENDAHULUAN}

Sistem Informasi Kesehatan (SIK) a dalah sistem yang mengintegrasikan pengumpulan, pengolahan, pelaporan data, dan penggunaan informasi yang diperlukan untuk meningkatkan efektivitas dan efisiensi pelayanan kesehatan melalui pengelohan yang lebih baik pada semua tingkat layanan kesehatan (WHO, 2004). Kemajuan atau kemunduran SIK selalu berkorelasi dan mengikuti perkembangan sistem kesehatan dan kemajuan Teknologi Informasi dan Komunikasi (TIK), bahkan memengaruhi sistem pemerintahan yang berlaku di suatu negara. Implementasi SIK akan berdampak pa da peningkatan performa pelayanan kesehatan, menghemat biaya operasional, dan meningkatkan kepuasan pasien (Shekelle \& Goldzweig, 2009).

Pera turan Menteri Kesehatan Republik Indonesia No. 97 Tahun 2015 menyatakan bahwa perkembangan TIK yang pesat menjadi peluang yang dapat memberikan kemudahan dalam penguatan dan pengembangan SIK (Kementerian Kesehatan, 2015). Kebutuhan akan TIK da lam SIK semakin meningkat seiring dengan tujuan pemerintah untuk meningkatkan kualitas, efisiensi, dan efektivitas pengelolaan serta penyelenggaraan pembangunan kesehatan terlebih da lam pelayanan kesehatan (Kementerian Kesehatan, 2015).

SIK telah menjadi penunjang utama dalam layanan kesehatan di Indonesia dan bagian penting yang tidak dapat dipisahkan dari Sistem Kesehatan Nasional(SKN). SIK yang berada di fasilitas pelayanan kesehatan berfungsi dalam manajemen rekam medis karena memuat riwayat dan layanan kesehatan yang diberika n kepada pasien. SIK juga menjadi dasar dalam penentuan pembiayaan layanan kepada pasien. SIK juga mampu menujukkan level kualitas sarana pelayanan kesehatan karena pengelolaan data dan informasi kesehatan di semua tingkat pemerintahan diterapkan secara sistematis dan terintegrasi guna mendukung manajemen kesehatan dalam rangka peningkatan pelayanan kesehatan kepada masyarakat (Soemitro et al., 2016; Zhao et al., 2020).

Hasil analisis situa si menunjukkan bahwa Dinas Kesehatan Kulon Progo telah memanfaatkan SIK dalam penyelenggaraan transaksi kesehatan di puskesmas yang bera da di wilayah kerja Kabupaten Kulon Progo. Dalam penerapannya, SIK memiliki komponen utama, yaitu data pasien. Data pasien memiliki nomor rekam medis sebagai kunci primer (primary key) yang menjadi kunci telusur data medis seorang pasien. Permasalahan yang terjadi di fa silitas pelayanan kesehatan ialah kelalaian ketika menangani nom or rekam medis, baik yang dilakukan oleh pasien maupun petugas, sehingga memunculkan duplikasi nomor rekam medis. Da lam kasus ini, seorang pasien memiliki banyak nomor rekam medis. Hal itu menyebabkan ketidaksinambungan rekam medis pada pasien tersebut. Ketidaksinambungan tersebut menyebabkan informasi yang diperoleh dari data rekam medis menjadi tidak akurat untuk digunakan oleh tenaga kesehatan atau dokter sebagai pertimbangan dalam menegakkan diagnosis dan memberkan pengobatan yang sesuai dengan kondisi kesehatan pasien.

Berdasarkan permasalahan tersebut, diperlukan sebuah mekanisme standar untuk melakukan identifikasi kesamaan data rekam medis pasien di fa silita s pelayanan kesehatan. Mekanisme standar yang akan diterapkan ialah sistem data cleansing yang merupakan salah satu bagian dari teknik dalam data mining untuk membuat basis data yang baik dan tidak mengandung duplikasi data.

Kegia tan pengabdian kepada masyarakat berupa implementasi teknik da ta cleansing untuk membantu mencegah dan mendeteksi duplikasi rekam medis ini dilaksanakan berdasarkan hasil penelitian dan pemanfaatan teknologi tepat guna di Dinas Kesehatan Kulon Progo, yaitu berupa framework "RESIK". Dalam kegiatan ini juga dilaksanakan pelatihan bagi tenaga perekam medis perihal penerapan sistem data cleansing dengan framework "RESIK" tersebut.

\section{METODE}

Kegiatan pengabdian kepada masyarakat ini dilaksanakan pada Maret - November 2019. Kegiatan dia wali dengan identifikasi masalah, ya itu duplikasi data rekam medis pasien pada basis data SIK Dinas Kesehatan Kulon Progo. Tim pengabdi kemudian mengurus izin pelaksanaan kegiatan ke Dinas Kesehatan Kulon Progo. Kepala Dinas Kesehatan Kulon Progo yang diwakili oleh Kepala Bidang Pelayanan Kesehatan sangat mendukung penerapan sistem data cleansing diDina s Kesehatan Kulon Progo.

Metode yang digunakan dalam pendeteksian kesamaan antardata pasien adalah metode data cleansing. Data cleansing akan memproses data dengan tiga metode sebagai berikut.

a. Mengakses langsung basis data Sistem Informasi Manajemen Puskesmas (SIMPUS) dengan hak akses tertentu.

b. Menggunakan service/API yang disediakan oleh SIMPUS. 
c. Import dan export melalui Excel.

Pada metode pertama dan kedua, framework "RESIK" dipasang pada server SIK Dina s Kesehatan Kulon Progo. Namun, hal tersebut ternyata berisiko terhadap keamanan data SIK sehingga framework "RESIK" dipasang pada server lokal untuk menjaga privasi data rekam medis. Setelah dijalankan, fram ework "RESIK" mengeluarkan rekomendasi data rekam medis yang terindikasi duplikat. Data rekam medis yang duplikat kemudian divalidasi oleh petugas rekam medis, selanjutnya dilakukan penggabungan.

\section{HASILDAN PEMBAHASAN}

Kegiatan pengabdian kepada masyarakat ini dilaksanakan berdasarkan hasil penelitian dan pemanfaatan teknologi tepat guna di Dinas Kesehatan Kulon Progo, yaitu berupa framework "RESIK". Kegia tan dimulai dengan sosialisasi kepada mitrauntuk menjaring masukan dari mitra, terutama mengenai parameter yang akan dijadikan acuan da lam proses deteksi duplikasi. Bahwa asumsi awal mengenai duplikasirekam medis ia lah satu pasien memiliki lebih dari satu nomor rekam medis kemudian ditetapkan. Berda sarkan hasil sosialisasi ditemukan kasus duplikasi pa da basis data SIMPUS diPuskesmas Sentolo 2, yaitu sa tu nomor rekam medis digunakan oleh banyak orang.

SIMPUS di Puskesmas Sentolo 2 kemudian dijadikan percontohan implementasi sistem data cleansing dengan framework "RESIK". SIMPUS Puskesmas Sentolo 2 direkomendasikan oleh pihak Dina s Kesehatan Kulon Progo untuk dijadikan bahan uji coba karena da ta SIMPUS Puskesmas Sentolo 2 selalu update dan sistem tersebut sudah terintegrasi dengan SIK Dinas Kesehatan Kulon Progo. Pengambilan sampling data dilakukan oleh Kepala Unit Rekam Medis Puskesmas Sentolo 2. Sampling data tersebut digunakan sebagai bahan uji coba pada workshop yang diselengga rakan 14 Agustus 2019 di Aula Sermo Kompleks Pemerintah Da erah Kabupaten Kulon Progo.

Setelah dilakukan uji coba, pihak Puskesmas Sentolo 2 menyarankan untuk menambahkan parameter pengecekan duplikasi, yaitu nomor rekam medis dan Nomor Induk Kependudukan (NIK). Saran penambahan nomor rekam medis dan NIK pada proses pengecekan duplikasi bertujuan untuk memudahkan petugas puskesmas, terutama perekam medis dalam menganalisis hasil dari keluaran sistem. Penambahan pa rameter dan kasus duplikasi a kan disesuaikan dengan metode data cleansing yang digunakan.

Setelah melaksanakan sosialisasi, tahap selanjutnya adalah mengurus perizinan untuk pengambilan data di Dinas Kesehatan Kulon Progo yang membawahi 21 puskesmas yang telah menggunakan SIMPUS. Tahap ini perlu dilakukan ka rena berkaitan dengan kerahasiaan data rekammedis yang harus dijaga dan hanya digunakan untuk pengembangan sistem informasi kesehatan Dinas Kesehatan Kulon Progo dalam pendeteksian duplikasi rekam medis melalui implementasi data cleansing menggunakan framework" RESIK".

Selain implementasi sistem, tim pengabdian kepada masyarakat juga mengadakan workshop yang berkaitan dengan kegiatan penyelenggaraan rekam medis di puskesmas untuk meningkatkan pengetahuan petugas kesehatan perihal pengelolaan rekam medis dan dokumen di puskesmas. Workshop dilaksanakan dua kali, yaitu "Workshop Pengelolaan Rekam Medis di Puskesmas Kabupaten Kulon Progo" pada 14 Agustus 2019 dan "Workshop Ta ta Kelola Dokumen Puskesmas" pada 29 Oktober 2019. Peserta workshop adalah perwakilan dari 21 puskesmas di Kabupaten Kulon Progo. Setiap puskesmas mengirimkan lima orang perwakilan yang terdiri atas dokter, dokter gigi, petugas rekam medis, perawat, dan bidan.

Pada workshop pertama dilakukan pre-test dan pada workshop kedua dilakukan post-test. Sebagian pertanyaan pada pre-test dan post-test digunakan untuk menggali persepsi dan kesadaran peserta workshop tentang pentingnya data rekam medis dan risiko duplikasi data rekam medis. Hasil pre-test menunjukkan bahwa hanya sekitar 55\% responden yang menyadari pentingnya data rekam medis dan risiko duplikasi data rekammedis. Adapun hasil posttest menunjukkan bahwa sekitar $85 \%$ responden menyadari pentingnya da ta rekam medis dan risiko duplikasi da ta rekam medis.

Materi yang disampaikan dalam workshop disesuaikan dengan kebutuhan peserta dan rencana pelatihan mencakup tujuan komprehensif, yaitu SMART (Specific, Measurable, Achievable, Realistic, Tangible). Kemampuan petugas kesehatan dalam penggunaan Electronic Medical Record (EMR) secara efisien akan bermanfaat pada pencapaian hasil klinis yang lebih baik, terutama di puskesmas yang menjadi layanan kesehatan primer. Kebijakan dan strategi pelatihan sangat berperan dalam implementasi teknologi yang sukses dan penggunaan sistem EMR yang berkelanjutan (Godinho et al., 2020; Li et al., 2020; Samadbeik et al., 2020) 


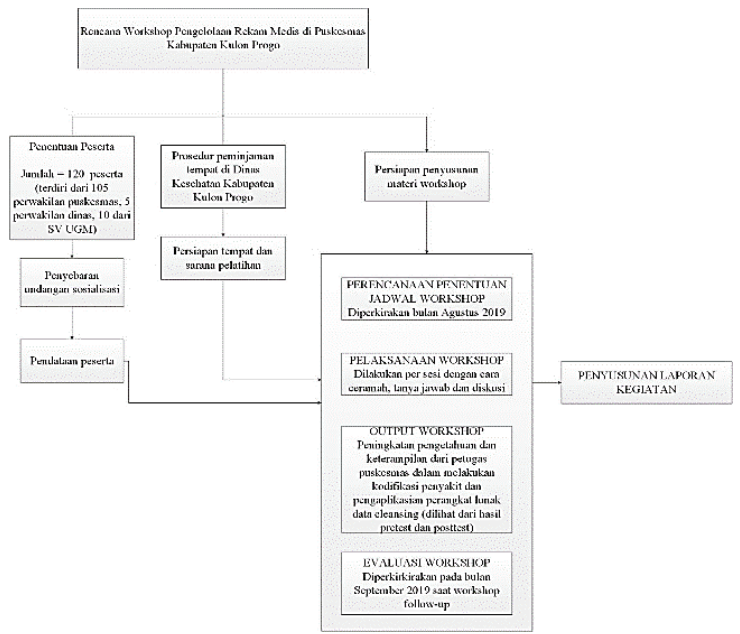

Gambar 1. Uraian kegiatan pengabdian kepada masyarakat

Dalam menunjang pelayanan kesehatan, puskesmas memanfaatkan teknologi informasi berupa SIMPUS untuk melakukan pencatatan dan pelaporan. SIMPUS memiliki ba sis data elektronik pasien dengan nomor rekam medis sebagai kunci primer. Dalam pelaksanaannya, tidak sedikit pasien dan petugas yang lalai dalam menangani nom or rekam medis sehingga menyebabkan duplikasi nomor rekam medis yang seharusnya tidak boleh terjadi. Luaran dari framework "RESIK" menunjukkan dua macam duplikasi. Duplikasi pertama ia lah seorang pasien memiliki dua a ta u lebih nomor rekammedis yang berbeda. Duplikasi kedua ialah nomor rekam medis digunakan oleh lebih darisa tu pasien.

Kegia tan ini dimulai dengan identifikasi duplikasi data rekam medis pasien pada basis da ta SIMPUS dengan framework "RESIK". Framework "RESIK" memproses data dengan tiga metode, yaitu mengakses langsung basis data SIMPUS dengan hak akses tertentu, menggunakan service/API yang disediakan oleh SIMPUS, serta melalui import dan export Excel. Pada metode pertama dankedua, sistem akan dipasang pada server SIMPUS. Akan tetapi, karena pemasangan tersebut berisiko untuk keamanan data SIMPUS, sistem kemudian dipasang pada server lokal. Untuk menjaga privasi data rekam medis, sistem hanya akan mengeluarkan rekomendasi rekam medis yang terindikasi duplikat. Selanjutnya, data rekam medis yang duplikat ini sebaiknya digabungkan.

Berdasarkan rekomendasi dari sistem, pengguna SIMPUS da pat menyatukan rekammedis yang duplikat setelah dilakukan validasi data-data duplikat tersebut sekaligus menemukan faktor penyebabnya. Setelah memastikan bahwa data yang direkomendasikan merupakan rekam medis duplikat, dilakukan penggabungan data rekam medis. Beberapa variabel yang menjadi penentu kesamaan adalah (a) nama pa sien, (b) jenis kelamin, (c) tanggal la hir pa sien, (d) ala mat tempat tinggal / KTP, dan (e) nomor rekam medis/ID.
Tim pengusul dan mitra sepakat untuk menerapkan sistem data cleansing dalam server SIK Dinas Kesehatan Kulon Progo. Tim pengabdian bersinergi dalam implementasi sistem ini sehingga dapat digunakan secara mandiri oleh mitra. Selain itu, pihak mitra juga membantu mengevaluasi keakuratan sistem ini dalam mengidentifikasi duplikasi rekam medis. Sinergi yang dilakukan berimplikasi pada perbaikan kualitas basis data rekam medis. Berdasarkan uraian di atas dapat diga mbarkan skema pemecahan masalah dalam kegiatan pengabdian kepada masyarakat ini yang didasarkan pada ha sil penelitian dan pemanfaatan teknologi tepat guna di Dinas Kesehatan Kulon Progo. Skema tersebut tampak pada Gambar 2 .

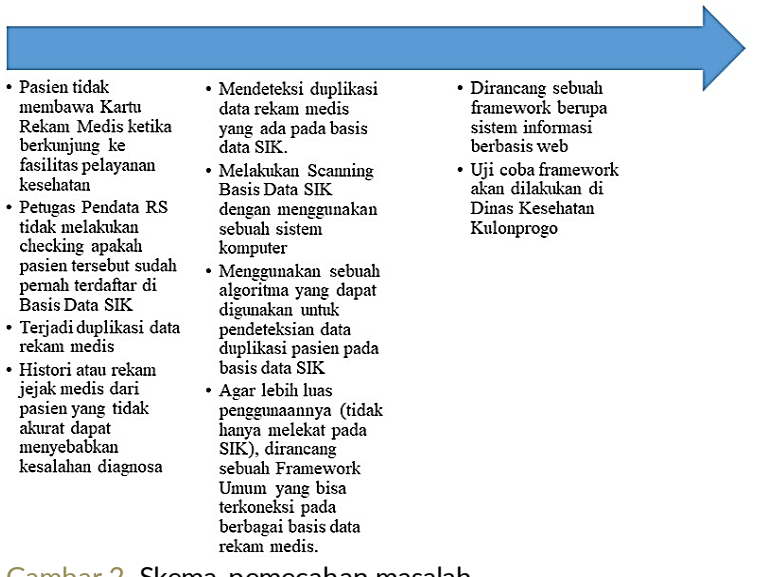

Gambar 2. Skema pemecahan masalah

Indikator kinerja pada kegiatan pengabdian kepada masyarakat berdasarkan hasil penelitian dan pemanfaatan teknologi tepat guna di Dinas Kesehatan Kulon Progo adalah terdeteksinya duplikasi rekam medis. Pada tahun pertama (2019), jum lah duplikasi data berkurang sebanyak 60\%. Pada tahun kedua, jumlah duplikasi da ta rekam medis diha rapkan dapat berkurang sebanyak 75\% dan pada tahun ketiga, jumlah duplikasi da ta rekam medis berkurang sebanyak $100 \%$.

Ketidaksinambungan data rekam medis pasien yang disebabkan duplikasi data rekam medis merupakan permasalahan yang sering terjadi. Hal tersebut diketahui dari hasil penelitian yang dilakukan oleh Gallagher (2012) dan Karlina et al. (2016). Kesinambungan data rekam medis sangat penting bagi tenaga kesehatan atau dokter, yaitu sebagai pertimbangan dalam menegakkan diagnosis dan memberikan pengobatan yang sesuai dengan kondisi kesehatan pasien (Ara vind Eye Care System, 2007). Kesalahan data klinis dapat mengakibatkan pengambilan keputusan yang tidak tepat dan penurunan kunjungan pasien.

Memprioritaskan kualitas data sa ngat diperlukan untuk memastikan bahwa pengambilan keputusan operasional didasarkan pada data a dministratif yang a kurat (Ward, Self, \& Froehle, 2016). Selain itu, perlu 
dilakukan evaluasi terhadap sistem yang sudah diimplementasikan secara sistematis di masa yang akan datang mela lui pendekatan metode yang tepat dan melibatkan kelompok pemangku kepentingan yang lebih luas (Andargoli et al., 2017; Erlirianto, Ali, \& Herdiyanti, 2015; Neame et al., 2020). Keberhasilan kegiatan pengabdian masyarakat ini ditunjukkan dengan diselesaikannya masalah duplikasi da ta rekam medis pa da SIMPUS dan meningkatnya pengetahuan pegawai puskesmas di wilayah Kabupaten Kulon Progo.

\section{KESIMPULAN}

Kegiatan pengabdian kepa da masyarakat yang dilaksanakan berdasarkan hasil penelitian dan pemanfaatan teknologi tepat guna di Dinas Kesehatan Kulon Progo bertujuan untuk melakukan deteksi duplikasi rekam medis di Dinas Kesehatan Kulon Progo dengan framework "RESIK". Beberapa kesimpulan yang dapat diambil dari pelaksanaan kegiatan ini sebagaiberikut.

a. Parameter yang digunakan dalam proses deteksi duplikasi data pasien terdiri atas nomor rekam medis, Nomor Induk Kependudukan, nama pasien, jenis kelamin, tanggal lahir pasien, dan alamat pasien.

b. Framework "RESIK" mampu mendeteksi duplikasi data rekam medis di Puskesmas Sentolo 2.

c. Rangkaian kegiatan pengabdian masyarakat mampu meningkatkan kesadaran peserta tentang pentingnya data rekam medis dan risiko duplikasi data rekam medis.

Berdasarkan pelaksanaan kegiatan pengabdian kepa da masyarakat disampaikan saran-saran sebagai berikut.

a. Framework "RESIK" diimplementasikan di semua puskesmas di Kabupaten Kulon Progo agar duplikasi data rekam medis dapat diidentifikasi.

b. Dilaksanakan kegiatan pendampingan di semua puskesmas di Kabupaten Kulon Progo sebagai wujud kerja sama antara Dinas Kesehatan Kabupaten Kulon Progo dan Universitas Gadjah Mada melalui skema mahas iswa praktik kerja lapangan dan magang.

\section{DAFTAR PUSTAKA}

Andargoli, A.E., Scheepers, H., Rajendran, D., \& Sohal, A. (2017). Health information systems evaluation framework s: A systematic review. International Journal of Medical Informatics, 97 , 195-209. https://doi.org/10.1016/j.ijmedinf.2016.10.008

Aravind Eye Care System. (2007). Medical Records Management In Eye Care Service. Graphico, Madurai.

Erlirianto, L.M., Ali, A.H.N., \& Herdiyanti, A. (2015). The Implementation of the Human, Organization, and Technology-Fit (HOT-Fit) Framework to Evaluate the Electronic Medical Record (EMR) System in a Hospital. Procedia Computer Science, 72, 580-587. https://doi.org/10.1016/j.procs .2015.12.166

Gallagher, A. (2012). The Risk of Duplicate Patient Records. Lorman Education Services. https://www.lorman.com/resources/whitepaper-therisk-of-duplicate-patient-records-109411 WP.

Godinho, M.A., Jonnagaddala, J., Gudi, N., Islam, R., Narasimhan, P., \& Liaw, S.T. (2020). Health for Integrated People-Centred Health Services in the Western Pacific: A Systematic Review. International Journal of Medical Informatics, 142(October 2019), 104259. https://doi.org/10.1016/j.ijmedinf.2020.104259

Karlina, D., Putri, I.A., Santoso, D.B., Studi, P., Rekam, D., Universitas, M., \& Mada, G. (2016). Kejadian Misfile dan Duplikasi Berkas Rekam Medis Sebagai Pemicu Ketidaksinambungan Data Rekam Medis. 1(1), 44-52.

Kementerian Kesehatan. (2015). Peraturan Menteri Kesehatan Nomor 97 Tahun 2015. Kementerian Kesehatan RI, Jakarta.

Li, X., Krumholz, H.M., Yip, W., Cheng, K.K., De Maeseneer, J., Meng, Q., \& Hu, S. (2020). Quality of primary health care in China: challenges and recommendations. The Lancet, 395(10239), 18021812. https://doi.org/10.1016/S0140-6736(20)30122-

Neame, M.T., Sefton, G., Roberts, M., Harkness, D., Sinha, I.P., \& Hawcutt, D.B. (2020). Evaluating health information technologies: A systematic review of framework recommendations. International Journal of Medical Informatics, 142(August), 104247. https://doi.org/10.1016/j.ijmedinf.2020.104247

Samadbeik, M., Fatehi, F., Braunstein, M., Barry, B., Saremian, M., Kalhor, F., \& Edirippulige, S. (2020). Education and Training on Electronic Medical Records (EMRs) for health care professionals and students: A Scoping Review. International Journal of Medical Informatics, 142(July), 104238. https://doi.org/10.1016/j.ijmedinf.2020.104238

Shekelle, P.G. \& Goldzweig, C.L. (2009). Costs and benefits of health information technology: an updated systematic review.

Soemitro, D., Sanjaya, G.Y., Sibuea, F., Roswiani, A., \& Maman. (2016). Tantangan e-Kesehatan di Indonesia. Buletin Jendala Data dan Informasi Kesehatan Kementerian Kesehatan RI, I, 17-21. https://doi.org/ISSN 2008-270X

Ward, M.J., Self, W.H., \& Froehle, C.M. (2016). Effects of Common Data Errors in Electronic Health Records on Emergency Department Operational Performance Metrics: A Monte Carlo Simulation. Academic Emergency Medicine, 1(1), 8-8. https://doi.org/10.1111/j.1553-2712.1994.tb02792.x

WHO. (2004). Developing Health Management Information Systems. Developing Health Management Information Systems: A Practical Guide for Developing Countries, 60.

Zhao, Y., Liu, L., Qi, Y., Lou, F., Zhang, J., \& Ma, W. (2020). Evaluation and design of public health information management system for primary health care units based on medical and health information. Journal of Infection and Public Health, 13(4), 491-496. https://doi.org/10.1016/j.jiph.2019.11.004 